\title{
Relevancia procesal del fracaso de las relaciones interpersonales en el matrimonio
}

\author{
The Procedural Significance of the Breakdown \\ in Interpersonal Relationships in Marriage
}

\section{Felipe Heredia Esteban \\ Prelado Auditor \\ Tribunal Apostólico de la Rota Romana \\ f.herediaesteban@gmail.com}

Resumen: El propósito principal de este artículo es situar adecuadamente el fracaso de las relaciones matrimoniales interpersonales en el ámbito del proceso canónico de declaración de nulidad del matrimonio. Para lograr este objetivo, es preciso adoptar, ante todo, una adecuada comprensión jurídica de la naturaleza y del contenido del «matrimonio in fieri»» e «in facto esse»; en segundo lugar, no despreciar el carácter declarativo del proceso de nulidad. El estudio del Magisterio Pontificio reciente permite concluir que la conexión entre el fracaso matrimonial y el proceso sigue siendo el mismo: el amor a la verdad; en otras palabras, la investigación sobre la verdad acerca de la cuestión del consentimiento de los esposos a través del proceso judicial de nulidad. Además, este magisterio nos pone en guardia frente a una desviada actuación pastoral en materia de fracasos matrimoniales, sugerida por algunos autores.

Palabras clave: Fracaso matrimonial, Declaración de nulidad del matrimonio, Vínculo esponsal, Relevancia de la cohabitación.
Abstract: The main purpose of this paper is to offer an apt account of the breakdown in interpersonal relationships within the context of the canonical process for the declaration of marriage nullity. To this end, a comprehensive legal understanding of the nature and content of marriage «in fieri» and «in facto esse» is required, followed by an account of the declarative status of the process of nullity. A reading of recent papal teaching in this regard prompts the conclusion that the connection between marriage breakdown and the nullity process remains the same: love of truth; in other words, an inquiry into the truth concerning the issue of spousal consent as part of the annulment process. Furthermore, this view guards against misguided pastoral practices that may have been proposed by other scholars.

Keywords: Marriage Breakdown, Declaration of Marriage Nullity, Marriage Bond, Relevance of Cohabitation. 


\section{INTRODUCCIÓN}

L

a relevancia procesal del fracaso de las relaciones interpersonales, cuestión por otra parte ampliamente tratada, en la doctrina ${ }^{1} \mathrm{y}$ en la jurisprudencia $^{2}$ en cuanto a su relación directa con la aplicación del número tercero del can. 1095 del CIC, puede esconder, sin embargo, un tema hoy especialmente actual: la relación entre el derecho canónico, la búsqueda de la verdad y la pastoral de la Iglesia a la hora de tratar el fenómeno del fracaso irremediable de la convivencia matrimonial ${ }^{3}$. Los dos recientes Sínodos extraordinario (2014) y ordinario (2015) sobre la familia y sus correspondientes conclusiones han puesto de relieve la necesidad de ubicar la reforma del proceso de nulidad matrimonial, introducida por el Papa Francisco, en el ámbito más amplio de la pastoral familiar ${ }^{4}$. Ante la realidad actual de tantos fracasos

${ }^{1}$ Cfr. P. MoneTa, Nullità e fallimento del matrimonio, en IDEM, Communitas vitae et amoris. Scritti di diritto matrimoniale canonico, Pisa University Press, Pisa 2013, 113-130; P. MONETA, Giudizio di nullità di matrimonio e vita coniugale, en IDEM, Communitas vitae et amoris. Scritti di diritto matrimoniale canonico, o. c., 131-148; C. PEÑa GARCÍA, El fracaso del matrimonio. Respuestas jurídicas civiles y canónicas y consideraciones pastorales, en A. Berástegui Pedro-VIEJO - B. Gómez BeNGOECHEA (coords.), Horizontes de la familia ante el S. XXI. Reflexiones con motivo del XXV aniversario del Instituto Universitario de la Familia, Universidad Pontificia Comillas, Madrid 2011, 237-258.

2 Cfr. coram YAACOUB, sent. diei 18 octobris 2005; coram De ANGELIS, sent. diei 12 novembris 2008, RRDec., vol. C, 309, n. 11; coram CABERLETTI, sent. diei 22 ianuarii 2009, sentencia no publicada; coram DE ANGELIS, sent. diei 25 iunii 2009, RRDec., vol. CI, 106, n. 26; coram CIANI, sent. diei 16 iulii 2009, sentencia no publicada.

3 JUan Pablo II, Ad Romanae Rotae Praelatos, auditores, officiales et advocatos anno iudiciali ineunte, Discurso del 18 de enero 1990 a la Rota romana, Acta Apostolicae Sedis 82 (1990) 875: «Convinta di ciò, l'Autorità ecclesiastica si studia di conformare la propria azione, anche nella trattazione delle cause sulla validità del vincolo matrimoniale, ai principii della giustizia e della misericordia. Essa perciò prende atto, da una parte, delle grandi difficoltà in cui si muovono persone e famiglie coinvolte in situazioni di infelice convivenza coniugale, e riconosce il loro diritto ad essere oggetto di una particolare sollecitudine pastorale. Non dimentica però, dall'altra, il diritto, che pure esse hanno, di non essere ingannate con una sentenza di nullità che sia in contrasto con l'esistenza di un vero matrimonio. Tale ingiusta dichiarazione di nullità matrimoniale non troverebbe alcun legittimo avallo nel ricorso alla carità o alla misericordia. Queste, infatti, non possono prescindere dalle esigenze della verità. Un matrimonio valido, anche se segnato da gravi difficoltà, non potrebbe essere considerato invalido, se non facendo violenza alla verità e minando, in tal modo, l'unico fondamento saldo su cui può reggersi la vita personale, coniugale e sociale. Un giudice pertanto deve sempre guardarsi dal rischio di una malintesa compassione che scadrebbe in sentimentalismo, solo apparentemente pastorale. Le vie che si discostano dalla giustizia e dalla verità finiscono col contribuire ad allontanare le persone da Dio, ottenendo il risultato opposto a quello che in buona fede si cercava».

${ }^{4}$ La Exort. Apost. Postsinodal Amoris Laetitia (La alegría del amor), sobre el amor en la familia, firmada por el Santo Padre el 19 de marzo, Solemnidad de San José, del año 2016, recoge los resultados de dos Sínodos sobre la familia convocados por Papa Francisco en el 2014 y en el 2015, cuyas Relaciones conclusivas son largamente citadas, junto a los documentos y enseñanzas de sus 
matrimoniales también en el seno de la Iglesia ¿cuál es la respuesta más pastoral que puede ofrecer el derecho vigente que tiene como ley suprema la salvación de las almas?

En este trabajo intentaremos exponer el tratamiento dado por el Magisterio pontificio al hecho cierto del fracaso matrimonial en cuanto posible prueba relevante para la declaración de nulidad; intentaremos precisar el objeto del proceso que tiene como eje la averiguación sobre la validez o no del consentimiento matrimonial y la ubicación que corresponde al análisis de los hechos acontecidos durante la convivencia matrimonial. Después expondremos algunas soluciones propuestas por algunos autores y que no pueden ser acogidas por contradecir la concepción básica del matrimonio pero que suponen un intento de solución ante la realidad del fracaso. Finalmente recordaremos algunos principios expuestos sobre nuestro tema en el Motu Proprio $\mathrm{Mi}$ tis Iudex Dominus Iesus y en la Exhortación Amoris Laetitia.

Ya desde el inicio conviene preguntarse: ¿'Tras la reforma del proceso de nulidad matrimonial introducida por el Papa Francisco con la promulgación

\footnotetext{
Predecesores y a las numerosas catequesis sobre la familia del mismo Papa Francisco. En el sexto capítulo de Amoris Laetitia el Papa afronta algunas vías pastorales que orientan para construir familias sólidas y fecundas según el plan de Dios. En esta parte la Exhortación hace un largo recurso a las Relaciones conclusivas de los dos Sínodos y a las catequesis del Papa Francisco y de Juan Pablo II. Entre otras cosas se habla también del acompañamiento de las personas abandonadas, separadas y divorciadas y se subraya la importancia de la reciente reforma de los procedimientos para el reconocimiento de los casos de nulidad matrimonial y se concluye: «Por otra parte, un gran número de Padres "subrayó la necesidad de hacer más accesibles y ágiles, posiblemente totalmente gratuitos, los procedimientos para el reconocimiento de los casos de nulidad"». La lentitud de los procesos irrita y cansa a la gente. Mis dos recientes documentos sobre esta materia han llevado a una simplificación de los procedimientos para una eventual declaración de nulidad matrimonial. A través de ellos también he querido «hacer evidente que el mismo Obispo en su Iglesia, de la que es constituido pastor y cabeza, es por eso mismo juez entre los fieles que se le han confiado». Por ello, «la aplicación de estos documentos es una gran responsabilidad para los Ordinarios diocesanos, llamados a juzgar ellos mismos algunas causas y a garantizar, en todos los modos, un acceso más fácil de los fieles a la justicia. Esto implica la preparación de un número suficiente de personal, integrado por clérigos y laicos, que se dedique de modo prioritario a este servicio eclesial. Por lo tanto, será, necesario poner a disposición de las personas separadas o de las parejas en crisis un servicio de información, consejo y mediación, vinculado a la pastoral familiar, que también podrá acoger a las personas en vista de la investigación preliminar del proceso matrimonial (cfr. Mitis Iudex Dominus Iesus, arts. 2-3)» (FrancIsco, Exort. Apost. Postsinodal Amoris Laetitia, n. 244). Cfr. C. M. Morán Bustos, Retos de la reforma procesal de la nulidad del matrimonio, Ius Canonicum 56 (2016) 9-40.

5 Cfr. A. Viana, ¿Son idóneos para el oficio eclesiástico los divorciados que contraen nuevo matrimonio civil?, Ius Canonicum 56 (2016) 515-553; C. J. ERRÁZurIz M., Matrimonio y justicia objetiva en la comunión eclesial: un aspecto del discernimiento pastoral propiciado por «Amoris Laetitia», Ius Canonicum 56 (2016) 731-738.
} 
del Motu Propio Mitis Iudex Dominus Iesus, ha cambiado el modo de situar el hecho cierto del fracaso de la convivencia matrimonial en relación con el proceso judicial?, ¿es ahora más relevante que antes?, ¿pueden encontrar los esposos que han sufrido las consecuencias de un fracaso matrimonial un trato procesal más benévolo según las nuevas normas en atención a un modo nuevo de hacer pastoral familiar conforme a la Exhortación Apostólica Amoris Laetitia $^{6}$ ?, ¿de tal manera que pudieran obtener con mayor facilidad la sentencia afirmativa que les permitiera contraer unas segundas nupcias? ¿Debiera ser el proceso de nulidad matrimonial una suerte de trámite pastoral para los matrimonios fracasados que les consintiera una nueva oportunidad ${ }^{7}$ ?

Entendemos por fracaso de las relaciones interpersonales un hecho negativo, que va más allá de la gran o simple conflictividad al interno de la convivencia matrimonial, el fracaso supone de facto la ruptura de la comunidad de vida y amor ante la imposibilidad culpable o no de los contrayentes para realizar la complementariedad propiamente conyugal en la donación y entrega mutuas; en terminología de la Exhortación Familiaris consortio se trataría de un matrimonio «irreparablemente destruido» (n. 84), si bien es cierto que las causas de la ruptura conyugal van más allá del fracaso de la relación interper-

${ }^{6}$ Francisco, Exort. Apost. Postsinodal Amoris Laetitia, n. 199: «El diálogo del camino sinodal llevaron a plantear la necesidad de desarrollar nuevos caminos pastorales, que procuraré recoger ahora de manera general. Serán las distintas comunidades quienes deberán elaborar propuestas más prácticas y eficaces, que tengan en cuenta tanto las enseñanzas de la Iglesia como las necesidades y los desafíos locales. Sin pretender presentar aquí una pastoral de la familia, quiero detenerme sólo a recoger algunos de los grandes desafíos pastorales».

7 C. M. Morán Bustos, Retos de la reforma procesal de la nulidad del matrimonio, cit., 10-11: «La Iglesia, que responde en sus orígenes al mandato del Señor de "id y haced discípulos a todos los pueblos, bautizándolos en el nombre del Padre y del Hijo y del Espíritu Santo", ha de ser una Iglesia "en salida" (nn. 20-24 EG), que no se limite al "simple administrar" lo que ya tiene (n. 25 EG), que venza la tentación de inmovilismo, que sea "casa abierta del Padre" (n. 47 EG), no una "aduana" que controle y e impida el acceso (nn. 47-49 EG), que se involucre en una "pastoral en conversión" (nn. 25-39 EG). Ésta es la predisposición que han de tener todos fieles y todas las comunidades cristianas, y es la predisposición que se exige en todos los ámbitos de la acción pastoral de la Iglesia, también en este ámbito concreto que es el de la administración de la justicia eclesial, ámbito que está directamente relacionado con la misión y con la acción evangelizadora de la Iglesia: así lo recordó expresamente el papa Francisco en su discurso a la plenaria del STSA de 8 de noviembre de 2013, en el que habló de "la conexión entre la acción de la Iglesia que evangeliza y la acción de la Iglesia que administra la justicia", y en el Discurso a la Rota Romana de 24 de enero de 2014. Por tanto, esta actividad judicial que la Iglesia presta a los fieles -muchos de ellos marcados tantas veces por las heridas de la vida y por el dolor que siempre comporta el fracaso de un proyecto como el conyugal-, pertenece directa y esencialmente a la acción pastoral de la Iglesia y a su misión evangelizadora, y en cuanto tal, también esta dimensión está necesitada de una "conversión pastoral", de esa "conversión de las estructuras" a la que se refiere el papa Francisco como idea recurrente». 
sonal. Pensemos en el caso de la exclusión hipotética de la indisolubilidad o de la prole; e igualmente que pueden darse matrimonios inválidamente celebrados que nunca fracasan, e incluso relaciones interpersonales aparentemente equilibradas que están fundamentadas en relaciones de tipo patológico.

Por relevancia procesal entendemos la mayor o menor repercusión jurídica que los orígenes del fracaso pueda tener en el ámbito de las causas de nulidad tipificadas en el Código de derecho canónico. Afirmar que todos los matrimonios fracasados sean nulos es falso, pero sí es cierto que la inmensa mayoría de los procesos de nulidad matrimonial se inician cuando la convivencia matrimonial se ha roto y es imposible la reconciliación ${ }^{8}$. Y es igualmente cierto que la gran mayoría de los esposos que han sufrido el fracaso al recurrir al proceso de nulidad buscan recuperar la libertad que les permita formalizar eclesiásticamente una nueva unión?.

\section{UBICACIÓN DE LA REALIDAD DEL FRACASO EN EL ANÁLISIS JURÍDICO} DEL MATRIMONIO

\subsection{Conceptos básicos referidos a la relación del matrimonio «in fieri» $e$ «in facto esse»}

Es sabido que el matrimonio lo produce el consentimiento de las partes legítimamente manifestado entre personas jurídicamente hábiles, consentimiento que ningún poder humano puede suplir (can. $1057 \$ 1$ ). Por tanto, el momento constitutivo del matrimonio y su causa eficiente es el acto de voluntad por medio del cual el varón y la mujer se entregan y aceptan mutuamente en alianza irrevocable para constituir el matrimonio (can. 1057 \$2). El

\footnotetext{
${ }^{8}$ Francisco, Mitis Iudex Dominus Iesus, art. 3, can. 1675: «El juez, antes de aceptar una causa, debe tener la certeza de que el matrimonio haya fracasado irreparablemente, de manera que sea imposible restablecer la convivencia conyugal».

9 Francisco, Discurso a los participantes en un curso organizado por el Tribunal del la Rota Romana, Sábado 12 de marzo de 2016, www.vatican.va: «El pasado 15 de agosto fueron promulgados los documentos Mitis Iudex Dominus Iesus y Mitis et Misericors Iesus, que han recogido los frutos del trabajo de la comisión especial instituida el 27 de agosto de 2014: casi un año de trabajo. Tales disposiciones tienen un objetivo eminentemente pastoral: mostrar la solicitud de la Iglesia hacia los fieles que esperan una rápida verificación de su situación matrimonial [...]. Es importante que la nueva normativa sea acogida y profundizada, en el contenido y en el espíritu, especialmente por los agentes de los Tribunales eclesiásticos, para ofrecer un servicio de justicia y de caridad a las familias. Para mucha gente, que ha vivido una experiencia matrimonial no feliz, la verificación de la validez o no del matrimonio representa una posibilidad importante; y estas personas deben ser ayudadas a recorrer el camino de la forma más ágil posible».
} 
término matrimonio es ambivalente: expresa su causa fundante (matrimonio in fieri) y el resultado producido (matrimonio in facto esse), pero, así como no puede confundirse el matrimonio con su causa eficiente tampoco puede identificarse el matrimonio in facto esse con la vida matrimonial, dato de interés a la hora de situar correctamente la realidad de un fracaso de la convivencia matrimonial ${ }^{10}$. El citado can. 1057, $\$ 2$, no es meramente reiterativo o de remisión, sino que destaca, explícitamente, dos factores importantes: el contenido del consentimiento matrimonial (matrimonio in fieri) es precisamente el instituto matrimonial (matrimonio in facto esse). Con palabras de la Gaudium et spes diremos que: «Fundada por el Creador y en posesión de sus propias leyes, la íntima comunidad conyugal de vida y amor se establece sobre la alianza de los cónyuges, es decir, sobre su consentimiento personal e irrevocable» ${ }^{11}$.

Por tanto, el consentimiento, «acto humano por el cual los esposos se dan y se reciben mutuamente», hace nacer la comunidad de vida como también la «institución confirmada por la ley divina» y el «vínculo sagrado» ${ }^{12}$. La comunidad de vida, así considerada, nos remite a la esencia del matrimonio in facto esse, como ha hecho notar el profesor Javier Hervada: «La inclinación natural tiende a unir al varón y a la mujer en una comunidad de personas, integrándolos en una unidad de personas que pertenece al género de relaciones jurídicas comunitarias» ${ }^{13}$. Y añade: «Ahora bien, supuesta esta unidad en las naturalezas, de ahí surge la conformación del matrimonio como una comunidad de vida y amor. En primer lugar, la unidad en las naturalezas une cuerpos

${ }^{10}$ Coram Heredia Esteban, sent. diei 29 octobris 2012, n. 5, sentencia no publicada: «Legislator haud praebet definitionem qua talem matrimonii sed descriptionem essentialem instituti matrimonialis. In eadam percipi potest veluti ambivalentia quaedam seu duplex aspectus termini matrimonii, id est, momentum constitutionis eiusdem per pactum coniugale, seu matrimonium in fieri, et effectus ab eo scaturiens, id est consortium totius vitae vel unio coniugalis in se ipsa, seu matrimonium in facto esse [...]. Matrimonium haud est confundendum cum eius causa fundante neque matrimonium in facto esse cum vita matrimoniali».

11 Concilium Oecumenicum Vaticanum II, Const. past. de Ecclesia in mundo huius temporis Gaudium et spes, Acta Apostolicae Sedis 58 (1966) 1067, n. 48: «Intima communitas vitae et amoris coniugalis, a Creatore condita, suisque legibus instructa, foedere coniugii seu irrevocabili consensu personali instauratur». Cfr. F. GIL Hellín, Il matrimonio e la vita coniugale, Libreria Editrice Vaticana, Città del Vaticano 1996, 129-165.

12 Ibid., 1067, n. 48: «Ita actu humano, quo coniuges sese mutuo tradunt atque accipiunt, institutum ordinatione divina firmum oritur, etiam coram societate; hoc vinculum sacrum intuitu boni, tum coniugum et prolis tum societatis, non ex humano arbitrio pendet». Cfr. F. GIL HeLLín, Il matrimonio e la vita coniugale, cit., 89-129.

13 J. Hervada - P. Lombardía, El Derecho del Pueblo de Dios. Derecho matrimonial, Eunsa, Pamplona $1973,216$. 
y almas; los cuerpos mediante el derecho mutuo sobre ellos, las almas por la unión de los yo personales mediante el amor debido o comprometido. En segundo término, quienes son uno en sus seres, son uno en sus destinos y sus vidas. Es, pues, claro que el matrimonio, siendo una unidad en las naturalezas, comporta una comunidad de vida y amor» ${ }^{14}$.

El Papa Francisco en la Exhortación Apostólica Amoris Laetitia con gran claridad enseña: «Según la tradición latina de la Iglesia, en el sacramento del matrimonio los ministros son el varón y la mujer que se casan, quienes, al manifestar su consentimiento y expresarlo en su entrega corpórea, reciben un gran don. Su consentimiento y la unión de sus cuerpos son los instrumentos de la acción divina que los hace una sola carne [...]. La Iglesia puede exigir la publicidad del acto, la presencia de testigos y otras condiciones que han ido variando a lo largo de la historia, pero eso no quita a los dos que se casan su carácter de ministros del sacramento ni debilita la centralidad del consentimiento del varón y la mujer, que es lo que de por sí establece el vínculo sacramental» (n. 75).

\subsection{El juicio sobre la nulidad del vínculo conyugal se dirige igualmente a analizar el matrimonio «in fieri» $e$ «in facto esse»}

El juicio sobre la nulidad del matrimonio se dirige principalmente a investigar su momento constitutivo para comprobar si pudo darse algún impedimento, defecto o vicio que pudiera provocar su invalidez, el análisis sobre la modalidad y condiciones del consentimiento emitido por los esposos constituye el eje central de la investigación y ello porque en gran medida todo el sistema matrimonial gira en torno a su momento fundacional, veremos que nada de lo que ocurra fuera o al margen del consentimiento emitido en forma canónica podrá tener relevancia de cara a su posible nulidad.

Por tanto, el devenir posterior de la convivencia matrimonial con toda su cadena de vicisitudes favorables o adversas, con su carga de generosidad o de egoísmo, de realización personal o de frustración no atañe directamente a la validez del matrimonio, por el contrario, todo lo que a ésta se refiere debe estar centrado en el momento histórico del consentimiento.

Siendo cierto lo anterior, sin embargo, esta concentración en el momento constitutivo del matrimonio no significa que los sucesos acontecidos du-

${ }^{14}$ J. Hervada, Esencia del matrimonio y consentimiento matrimonial, Persona y Derecho 9 (1982) 154. 
rante la convivencia matrimonial sean completamente ignorados. Es histórica la sentencia del Cardenal Dino Staffa, Prefecto de la Signatura Apostólica, cuando reconoce que la brevedad de la convivencia matrimonial puede ser un indicio de la nulidad del vínculo en relación con varios capítulos de nulidad, sea la violencia o el miedo o la exclusión o la incapacidad: «Brevitas durationis vitae coniugalis semper habita est uti indicium nullitatis vinculi, sive ob vim et metum, sive ob positivum actum voluntatis excludentis aliquod elementum essentiale matrimonii, sive ob incapacitatem subiectivam alterutrius coniugum ad verum consensum matrimonialem praestandum, dummodo brevitas vitae coniugalis et defectus integrationis vitae coniugalis non sint tribuendis causis extrinsecis, v. gr. eventui impreviso qui coniuges dividit» ${ }^{15}$.

No podemos olvidar que el efecto producido por el consentimiento matrimonial no es otro que un consorcio de toda la vida ordenado por su propia índole natural al bien de los cónyuges y a la generación y educación de la prole conforme al can. 1055 y que la constitución apostólica Gaudium et spes lo describe como una «íntima comunidad conyugal de vida y amor» ${ }^{16}$, lo cual nos conduce a orientar el régimen jurídico de la nulidad sobre la base de esta realidad: cada vez más el derecho tiende a conceder eficacia invalidante a aquellas circunstancias que impiden en el plano humano la realización en lo esencial de tal comunión de vida conyugal pero siempre en estrecha relación con su momento fundante.

Una clara confirmación de ello la encontramos en los motivos de nulidad introducidos por primera vez en el Código de 1983. Es emblemática la incapacidad para asumir las obligaciones esenciales del matrimonio prevista en el n. 3 del canon 1095 en la que se puede situar con mayor claridad el fracaso de las relaciones interpersonales. En este caso el motivo de nulidad está puesto en estrechísima conexión con la comunión de vida que los esposos están llamados a realizar. Es evidente que la efectiva subsistencia de este capítulo de nulidad no puede sino emerger concretamente en el curso de la vida conyugal. Y en ocasiones, sólo cuando viene puesta en práctica la vida matrimonial se pueden revelar las carencias de la capacidad de la persona que la convierten en no idónea para hacer frente a las obligaciones matrimoniales esenciales. En este tipo de juicios habrá que

15 D. STAFFa, Iurisprudentia Supr. Tribunalis Signaturae Apost. Dioecesis Ultraiecten. Nullitatis matrimonii (29 nov. 1975), Periodica de re morali canonica liturgica 65 (1977) 297.

16 Concilium Oecumenicum Vaticanum II, Const. past. de Ecclesia in mundo huius temporis Gaudium et spes, cit., 1067, n. 48: «Intima communitas vitae et amoris coniugalis». 
comenzar por el conocimiento de la experiencia de la vida conyugal, de su falta o al menos incompleta realización de la comunidad de vida y amor. Teniendo en cuenta esta base fundamental la valoración buscará referirse al momento constitutivo del matrimonio, en el sentido de verificar que la incapacidad demostrada del contrayente estaba ya presente al menos en la causa psíquica que la ha producido en el momento de la prestación del consentimiento matrimonial.

Siendo cierto lo anterior no debe confundirse la vida común externa o efectiva con ese nivel esencial de la relación de comunión que anteriormente hemos expuesto. El Vaticano II se recrea en la consideración del orden divino de la comunicación de los cónyuges dimanante de su constitución en una «especie de Iglesia doméstica» ${ }^{17}$ : «Aquí los cónyuges tienen su propia vocación: el ser mutuamente y para sus hijos testigos de la fe y del amor de Cristo. La familia cristiana proclama en voz muy alta tanto las presentes virtudes del reino de Dios como la esperanza de la vida bienaventurada ${ }^{18}$.

Estamos de acuerdo con el profesor Javier Hervada cuando concluye: «Decir que el matrimonio es una comunidad de vida y amor es una gran verdad; mas definir el matrimonio como tal, colocar lo más esencial y radical del matrimonio en esa comunidad, me parece un error no pequeño. $Y$ es que la comunidad de vida y amor, si se prescinde de una unión más básica y radical entre los cónyuges, queda referida sólo a la existencia, al desarrollo vital del matrimonio, pues vida y amor, sin una raíz que los sustente, son puro devenir, puro hecho, despojando de este modo al matrimonio del vínculo jurídico. La comunidad de vida y amor nace de la esencia del matrimonio, pero no es su esencia» ${ }^{19}$. O lo que es lo mismo: «El matrimonio, antes que ser, como es, unión en la actividad, en la vida y en el amor, es vínculo jurídico en el ser, es unidad en las naturalezas. Ahora bien, supuesta esta unidad en las naturalezas, de ahí surge la conformación del matrimonio como una comunidad de vida y amor $\gg^{20}$. Esto supuesto, de ahí nace otra conclusión no menos evidente: es preciso dis-

17 Concilium Oecumenicum Vaticanum II, Const. dogm. de Ecclesia Lumen Gentium, Acta Apostolicae Sedis 57 (1966) 16, n. 11: «In hac velut Ecclesia domestica parentes verbo et exemplo sint pro filiis suis primi fidei praecones, et vocationem unicuique propriam, sacram vero peculiari cura, foveant oportet».

18 Concilium Oecumenicum Vaticanum II, Const. dogm. de Ecclesia Lumen Gentium, cit., 4041, n. 35: «Ibi coniuges propriam habent vocationem, ut sibi invicem et filiis sint testes fidei et amoris Christi. Familia christiana tum praesentes virtutes Regni Dei tum spem vitae beatae alta voce proclamat».

19 J. HERVADA, Esencia del matrimonio y consentimiento matrimonial, cit., 152.

20 Ibid. 
tinguir con claridad cuanto contribuye al buen éxito de la vida matrimonial y lo que constituye una causa de nulidad del matrimonio.

Diferenciada así la comunidad de vida ${ }^{21}$, como consecuencia de la esencia del matrimonio, respecto de la comunicación de los casados, que no puede ser confundida con la esencia del matrimonio, por más que esté ordenada por el derecho, resulta particularmente luminosa, respecto del sentido en que se puede hablar de la capacidad para hacer la comunidad de vida, estas palabras dirigidas por Benedicto XVI en 2009 a la Rota Romana: «En este sentido, la capacidad debe ser puesta en relación con lo que es esencialmente el matrimonio, es decir, "la comunión íntima de vida y amor conyugal, fundada por el Creador y estructurada con leyes propias" (Gaudium et spes, 48), y, de modo particular, con las obligaciones esenciales inherentes a ella, que deben asumir los esposos (cfr. can. 1095, n. 3). Esta capacidad no se mide en relación a un determinado grado de realización existencial o efectiva de la unión conyugal mediante el cumplimiento de las obligaciones esenciales, sino en relación al querer eficaz de cada uno de los contrayentes, que hace posible y operante esta relación ya desde el momento del pacto nupcial. Así pues, el discurso sobre la capacidad o incapacidad tiene sentido en la medida en que se atañe al acto mismo de contraer matrimonio, ya que el vínculo creado por la voluntad de los esposos constituye la realidad jurídica de la una caro bíblica (cfr. Gn 2,24; Mc 10,8; Ef 5,31; can. 1061, 1), cuya subsistencia válida no depende del comportamiento sucesivo de los cónyuges a lo largo de la vida matrimonial. De forma diversa, en la visión reduccionista que desconoce la verdad sobre el matrimonio, la realización efectiva de una verdadera comunión de vida y de amor, idealizada en el plano del bienestar puramente humano, resulta esencialmente dependiente sólo de factores accidentales, y no del ejercicio de la libertad humana sostenida por la gracia. Es verdad que esta libertad de la naturaleza humana, "herida en sus propias fuerzas naturales" e "inclinada al pecado" (Catecismo de la Iglesia católica, n. 405), es limitada e imperfecta, pero no por ello es inauténtica y insuficiente para realizar el acto de autodeterminación de los contrayentes que es el pacto conyugal, que da vida al matrimonio y a la familia fundada en él» ${ }^{22}$.

${ }^{21}$ Cfr. J. Hervada, Una caro. Escritos sobre el matrimonio, Eunsa, «Instituto de Ciencias para la Familia», Pamplona 2000, 198-202.

22 Benedictus XVI, Ad sodales Tribunalis Romanae Rotae, Acta Apostolicae Sedis 101 (2009) 126127: «In questo senso, la capacità deve essere messa in relazione con ciò che è essenzialmente il matrimonio, cioè "l'intima comunione di vita e di amore coniugale, fondata dal Creatore e strutturata con leggi proprie", e, in modo particolare, con gli obblighi essenziali ad essa inerenti, da 
Con estas palabras el Papa Benedicto XVI sitúa muy bien la diferencia entre el matrimonio comunidad de vida y amor o lo que es lo mismo «la realidad jurídica de la una caro bíblica» surgida válidamente del consentimiento, con el devenir existencial de la convivencia conyugal abierta a tantas vicisitudes y contingencias a veces extrínsecas a los propios esposos y que pueden poner a prueba la estabilidad del consorcio conyugal ${ }^{23}$; al mismo tiempo entra en juego el uso que los esposos hagan de su libertad en orden al cumplimiento de las obligaciones esenciales del matrimonio ${ }^{24}$. Por todo ello, si bien el transcurso de la convivencia matrimonial debe ser analizado con referencia al acto primordial de consentir, sin embargo, precisamente la capacidad para consentir es la misma que para poner en práctica esa realidad jurídica que es la una caro bíblica y esa capacidad no se puede medir en atención a conseguir un determinado grado de satisfacción o gratificación psicológico-espiritual sino al querer eficaz de cada uno de los contrayentes, es decir al uso humano correcto de la propia libertad en orden a la donación y entrega de sí mismos en todo lo que sea conyugal. Esto permite ubicar con parámetros concretos la capacidad para consentir y por tanto asumir los derechos y obligaciones esenciales matrimoniales. Una cuestión relevante es cuando el uso de la libertad viene atacado o cercenado gravemente impidiendo la finalidad pretendida de construir esa realidad jurídica que es la una caro bíblica.

assumersi da parte degli sposi. Questa capacità non viene misurata in relazione ad un determinato grado di realizzazione esistenziale o effettiva dell'unione coniugale mediante l'adempimento degli obblighi essenziali, ma in relazione all'efficace volere di ciascuno dei contraenti, che rende possibile ed operante tale realizzazione già al momento del patto nuziale. Il discorso sulla capacità o incapacità, quindi, ha senso nella misura in cui riguarda l'atto stesso di contrarre matrimonio, poiché il vincolo messo in atto dalla volontà degli sposi costituisce la realtà giuridica dell'una caro biblica, la cui valida sussistenza non dipende dal successivo comportamento dei coniugi lungo la vita matrimoniale. Diversamente, nell'ottica riduzionistica che misconosce la verità sul matrimonio, la realizzazione effettiva di una vera comunione di vita e di amore, idealizzata su un piano di benessere puramente umano, diventa essenzialmente dipendente soltanto da fattori accidentali, e non invece dall'esercizio della libertà umana sorretta dalla grazia. É vero che questa libertà della natura umana, "ferita nelle sue proprie forze naturali" ed "inclinata al peccato", è limitata e imperfetta, ma non per questo è inautentica e insufficiente a realizzare quell'atto di autodeterminazione dei contraenti che è il patto coniugale, che dà vita al matrimonio e alla famiglia fondata su esso». Cfr. BeNEDICTO XVI, Discurso al Tribunal de la Rota Romana con motivo de la inauguración del año judicial, Sala Clementina, Jueves 29 de enero de 2009, www.vatican.va.

${ }^{23}$ M. Á. OrTiZ, La capacità consensuale nel recente Magistero pontificio. Introduzione ai lavori, en H. FranCESCHI - M. Á. ORTIZ, Discrezione di giudizio e capacità di assumere: la formulazione del canone 1095, Giuffrè Editore, Milano 2013, 13-21.

${ }^{24}$ M. Á. OrTIZ, Capacità consensuale ed essenza del matrimonio, Ius Ecclesiae 21 (2009) 481-493. 


\subsection{Finalidad del proceso declarativo de nulidad matrimonial}

El proceso declarativo de nulidad matrimonial ha sido creado y tiene por finalidad determinar si un matrimonio fue celebrado válidamente o no por carecer en su momento constitutivo de algún elemento o propiedad esencial necesaria para su validez; en palabras del Papa Benedicto XVI, el «proceso canónico de nulidad del matrimonio constituye esencialmente un instrumento para certificar la verdad sobre el vínculo conyugal. Por consiguiente, su finalidad constitutiva no es complicar inútilmente la vida a los fieles, ni mucho menos fomentar su espíritu contencioso, sino sólo prestar un servicio a la verdad. Por lo demás, la institución del proceso en general no es, de por sí, un medio para satisfacer un interés cualquiera, sino un instrumento cualificado para cumplir el deber de justicia de dar a cada uno lo suyo» ${ }^{25}$. Por tanto y en línea de principios el proceso no tiene por objeto fallar que el matrimonio ha fracasado y en consecuencia no busca directamente demostrar el porqué del fracaso de la convivencia matrimonial ni tampoco buscar las causas de ese fracaso e igualmente no pretende regular sus efectos. Su finalidad principal es alcanzar la verdad objetiva sobre la validez o no del consentimiento matrimonial, se trata de un servicio a la verdad por encima de todo. Siendo todo ello cierto, sin embargo, es evidente que muchos o al menos algunos de los matrimonios fracasados están afectados de alguna causa de nulidad matrimonial.

El Papa también señala la verdadera dimensión pastoral de la búsqueda de la verdad sobre el vínculo conyugal, cuando concluye: «su valor pastoral [...] no puede separarse del amor a la verdad. En efecto, puede suceder que la caridad pastoral a veces esté contaminada por actitudes de complacencia con respecto a las personas. Estas actitudes pueden parecer pastorales, pero en realidad no responden al bien de las personas y de la misma comunidad eclesial» ${ }^{26}$. Es, por tan-

${ }^{25}$ Benedicto XVI, Ad Tribunal Rotae Romanae, Acta Apostolicae Sedis 98 (2006) 136: «Il processo canonico di nullità del matrimonio costituisce essenzialmente uno strumento per accertare la verità sul vincolo coniugale. Il suo scopo costitutivo non è quindi di complicare inutilmente la vita ai fedeli né tanto meno di esacerbarne la litigiosità, ma solo di rendere un servizio alla verità. L'istituto del processo in generale, del resto, non è di per sé un mezzo per soddisfare un interesse qualsiasi, bensì uno strumento qualificato per ottemperare al dovere di giustizia di dare a ciascuno il suo». Cfr. Benedicto XVI, Discurso a los Prelados Auditores, Defensores del Vínculo y Abogados de la Rota Romana, Sábado 28 de enero de 2006, www.vatican.va.

${ }^{26}$ BENEDICTO XVI, Ad Tribunal Rotae Romanae, cit., 137-138: «Il criterio della ricerca della verità, come ci guida a comprendere la dialettica del processo, così può servirci per cogliere l'altro aspetto della questione: il suo valore pastorale, che non può essere separato dall'amore alla verità. Può avvenire infatti che la carità pastorale sia a volte contaminata da atteggiamenti compiacen- 
to, evidente que el proceso canónico en el buscar la verdad agota toda su función pastoral, entender la pastoral como una salida complaciente para los esposos al margen de la verdad objetiva sobre el vínculo supone una verdadera traición a la justicia debida y, por tanto, a la dimensión intrínsecamente pastoral del proceso ${ }^{27}$.

\section{Propuestas de solución en el ámbito del proceso \\ PARA EL FRACASO MATRIMONIAL}

El fracaso de las relaciones interpersonales en cuanto sinónimo de fracaso irremediable de la convivencia matrimonial abierto a una posible solución en el ámbito judicial que otorgara la libertad a los cónyuges para contraer nuevas nupcias ha sido analizado por algunos autores ${ }^{28}$, sobre todo desde una perspectiva teológica ofreciendo hipótesis de solución en el ámbito del proceso canónico que sirvieran de alternativa, por inadecuado, al vigente sistema de declaración de nulidad matrimonial. Estos autores vienen a decir que las modernas patologías del matrimonio difícilmente pueden ser tratadas por medio del actual derecho matrimonial y que los muy frecuentes fracasos matrimoniales ponen en tela de juicio la actual doctrina sobre el matrimonio: «Nos parece que somos fieles a la tradición repitiendo las formulitas jurídicas o catequéticas elaboradas para otro mundo, para otro hombre, para otra mujer, para otra familia» ${ }^{29}$. Se afirma que lo que está en juego no es un «divorcio católico» sino

ti verso le persone. Questi atteggiamenti possono sembrare pastorali, ma in realtà non rispondono al bene delle persone e della stessa comunità ecclesiale». Cfr. BENEDiCTO XVI, Discurso a los Prelados Auditores, Defensores del Vínculo y Abogados de la Rota Romana, Sábado 28 de enero de 2006, www.vatican.va.

27 Coram Heredia Esteban, sent. diei 16 iulii 2015, n. 3, no publicada: «Matrimonii sacramentum Ecclesia peculiari semper pastorali sollicitudine prosecuta est, cum sit sibi conscia matrimonium et familiam unum e bonis pretiosissimis generis hominum esse. Etenim salus personae et societatis humanae ac christianae arcte cum fausta condicione communitatis coniugalis et familiaris conectitur. Cuius quidem peculiaris pastoralis sollicitudinis testimonium est perampla tractatio, quam Concilium Vaticanum II eidem tribuit argumento. Summi autem Pontifices necnon totius orbis Episcopi numquam cessaverunt perfectissimam matrimonii ac familiae imaginem iterum iterumque fidelibus proponere atque urgere, simul respondentes huius nostrae aetatis quaestionibus, quemadmodum contigit cum Romanus Pontifex Franciscus Litteras Apostolicas Mitis Iudex Dominus Iesus promulgavit die 15 augusti 2015. Inter multiplicia huius studiosae curae signa recentioribus temporibus reddita, eminent profecto Episcoporum Synodus a die IV ad XXV octobris anno MMXV celebrata. Inter praecipua munera missioni Ecclesiae concredita ad matrimonium et familiam quod attinet, habendum sane est officium omnibus consilium Dei de matrimonio ac familia declarandi, cuius plenum vigorem et promotionem humanam et christianam in tuto collocet».

${ }^{28}$ Cfr. A. GRILLO, Matrimonios indisolubles y matrimonios fracasados, un reto para la pastoral: teología con visión de futuro y teología corta de vista, Phase. Revista de pastoral litúrgica 324 (2014) 644-653.

29 A. GRILLO, Matrimonios indisolubles y matrimonios fracasados..., cit., 648. 
«una doctrina y una disciplina del matrimonio que sepa reflexionar con delicadeza, profundidad y coraje la gran transformación que ha experimentado la vida de los hombres y de las mujeres en los últimos siglos. Ante estas transformaciones, continuar razonando únicamente con categorías de validez y nulidad [...] y traducir el don positivo en un término negativo como es la indisolubilidad representa un grave pecado de omisión por parte de la Iglesia» ${ }^{30}$.

a) El primer autor (Andrea Grillo) profesor en el Pontificio Ateneo San Anselmo de Roma indica que ante el matrimonio fracasado no cabe una respuesta anclada en el sistema de validez o nulidad, sino que es necesario replantear la comprensión del vínculo matrimonial: «Un planteamiento jurídico que se enfrente a las cuestiones de las patologías matrimoniales con la categoría de la validez/indisolubilidad y de la nulidad/reversibilidad actuará y removerá el único nivel realmente problemático, es decir, la crisis del vínculo mismo» ${ }^{31}$. Y añade: «La verdad del matrimonio no se encuentra, verdaderamente, custodiada por una teoría objetiva del vínculo [...]. Sólo una teoría intersubjetiva del vínculo puede tener la capacidad de ofrecer una buena solución a los matrimonios fracasados. No podemos ya quedar por más tiempo prisioneros de la alternativa válido/nulo. Podremos afrontar con mayor serenidad, la hipótesis de que lo que muere puede ser el vínculo. Que la unión de los esposos puede/debe tener una historia y que en esta historia pueda dar fruto o morir, constituye una cuestión teórica preliminar que define las tradiciones pre-modernas y tardo-modernas del mismo Evangelio del matrimonio [...]. Nadie dispone del vínculo. Pero el sujeto y la Iglesia pueden constatar, con el oportuno proceso, que el vínculo se encuentra ya muerto» ${ }^{32}$.

El autor mencionado afirma: «Lo que el Concilio Vaticano II nos quiso enseñar, de manera magistral, fue que se diera una gran reconciliación entre la doctrina y la experiencia. En nuestros días junto con el relanzamiento de esta gran opción, podríamos convenir en una nueva atención de aquellas personas que ven "morir" el vínculo de su matrimonio y no saben cómo poder aceptar las únicas dos soluciones que la Iglesia ofrece a su consciencia: o reconocer que aquel vínculo no existió nunca o empeñarse en hacer morir todo lo que en la nueva realidad de pareja podría contradecirlo» ${ }^{33}$.

30 Ibid., 646.

31 Ibid.

32 Ibid., 651.

33 Ibid., 652. 
Este autor propone que el vínculo matrimonial se identifique sustancialmente con la propia convivencia matrimonial de tal manera que las vicisitudes que la acompañan puedan repercutir en su propia subsistencia, y por tanto que cuando se produzca el fracaso irremediable de la convivencia conyugal con independencia de sus causas la Iglesia pueda certificar su desaparición, quedando libres los esposos para formalizar otro nuevo compromiso matrimonial. Denuncia los profundos cambios antropológicos acontecidos en los últimos doscientos años con su consiguiente repercusión en la comprensión práctica de la libertad del hombre tardo moderno y su particular manifestación en la vida familiar, mientras que la doctrina teológica y el derecho canónico han seguido anclados en ideas y términos incompatibles con el concepto moderno del hombre y de la familia sin que se haya dado el correspondiente ajuste ideológico.

En consecuencia, presenta una nueva comprensión del vínculo matrimonial en que prime la realidad intersubjetiva de la convivencia matrimonial frente a una visión objetiva e institucionalizada desprovista del necesario respeto a la persona que debe estar por encima de la institución. Por tanto, si el vínculo matrimonial sigue las vicisitudes del transcurso histórico de la convivencia matrimonial concluye que cuando se da un fracaso irremediable la Iglesia por medio de un proceso judicial debe certificar la muerte del vínculo conyugal.

Este autor parece ignorar que el consentimiento pone en acto lo que en la naturaleza humana existe en potencia, esto hace que ese consentimiento sea verdadera causa eficiente del matrimonio, pero el vínculo causado «no es anudado por el consentimiento sino por la naturaleza [...]. No es, pues, el vínculo consensual, sino natural; y como es un vínculo jurídico, decir natural es decir de derecho natural. El matrimonio no es un vínculo cuya existencia penda del consentimiento, porque no es un vínculo o relación consistente en una voluntad continuada y comprometida -en una voluntad debida, obligada-, sino que es una relación jurídica de derecho natural. La deuda nacida tiene un aspecto de voluntad obligada, pero es principal y básicamente una deuda de derecho natural. O dicho de otro modo la coposesión, la participación y la comunicación mutuas en las que consiste la unidad en las naturalezas son un vínculo de derecho natural $\gg^{34}$. Así podremos percibir el sentido de la inequívoca afirmación evangélica sobre el vínculo conyugal: «Deus coniunxit» ${ }^{35}$, el vínculo lo anudó Dios a través de la naturaleza, con un exquisito respeto a la libertad del hombre; y de

\footnotetext{
34 J. HerVADA, Esencia del matrimonio y consentimiento matrimonial, cit., 158.

35 Mt 19,6: «Itaque iam non sunt duo sed una caro. Quod ergo Deus coniunxit, homo non separet».
} 
tal forma, que puede decirse, a la vez, que el derecho natural -esto es, Diosunió a los casados y que el consentimiento es la causa eficiente de ese vínculo.

b) Un segundo autor aun reconociendo la indisolubilidad absoluta del matrimonio rato y no consumado, no encuentra ningún inconveniente en proponer una declaración de nulidad «ex nunc» para aquellos matrimonios irremediablemente fracasados, insistiendo en que no se trata de una disolución del vínculo sino más bien de una decisión meramente declarativa. Para argumentar su postura se sirve de la analogía empleada por San Roberto Belarmino entre el sacramento de la Eucaristía y el del matrimonio; así como el primero no sólo es sacramento en el momento en que se realiza, sino también durante el tiempo que permanece, del mismo modo sucede en el matrimonio que permanece mientras viven los esposos: « $\mathrm{Si}$ no hay pan y no hay vino no puede haber sacramento. El pan tiene que ser pan y el vino tiene que ser vino. La analogía con el matrimonio se hace patente: el amor de los cónyuges, que tiene que reunir unos grados mínimos de humanidad para ser un amor sacramentalizable, debe también perseverar y mantenerse para seguir siendo sacramento. Ese tejido o urdimbre de relaciones interpersonales -lo permanente del matrimonio- tiene que ser un tejido o urdimbre de relaciones por lo menos mínimamente interpersonales [...]. Las relaciones interpersonales son como las especies consagradas del pan y del vino [...]. Si hablando de la Eucaristía cesa el sacramento desde el momento en que las especies consagradas se corrompen, ¿no habrá que decir también, por analogía, y refiriéndonos al otro sacramento permanente -el matrimonio- que cesa cuando se corrompen las relaciones interpersonales o humanas? [...] Si el matrimonio se corrompe en un momento dado de su desarrollo, por las razones que sean, y se convierte en una comunidad de desamor o de odio, es decir, en un anti signo del Amor de Cristo a su Iglesia, ¿no habría que pensar que cesa el sacramento permanente del matrimonio al igual que cesa el sacramento permanente de la Eucaristía cuando se corrompen las especies sacramentales?» ${ }^{36}$.

El autor concluye que la solución para aquellos «matrimonios que sí fueron sacramentos y fueron consumados, pero que, en un momento dado, se convierten en matrimonios irreversiblemente rotos, además de la clásica declaración de nulidad ex tunc [...] se sugiere como teológicamente posible una declaración ex nunc [...] no sería disolutiva del matrimonio sino meramente declarativa. Los tribunales de la Iglesia se limitarían a declarar que el matrimonio

${ }^{36}$ J. M. Lahidalga AgutrRe, A propósito de los matrimonios irremediablemente fracasados: una hipótesis de trabajo, Scriptorium victoriense 40 (1993) 295-317. 
cristiano en cuestión había dejado de ser sacramento. Y con todas sus consecuencias [...]. En los matrimonios irremediablemente fracasados o rotos no se disuelve nada. Se trata de salvar una pareja, levantando simplemente un acta de defunción. Valga la metáfora para expresar esa muerte moral que significa la corrupción de las especies consagradas o relaciones interpersonales de la pareja matrimonial» ${ }^{37}$. Y añade: «Cuando se trata de matrimonios cristianos que fueron válidos desde el principio, pero que después, tras cierto tiempo -incluso años- se deterioran y fracasan sin remedio, pensamos que cabría no una disolución sino una mera declaración de nulidad ex nunc, esto es, desde el momento, posterior a su válida celebración, en que se constata su fracaso irremediable» ${ }^{38}$.

De nuevo comprobamos la errónea comprensión de elementos esenciales que tocan tanto la teología del matrimonio como el propio derecho natural; este autor identifica las vicisitudes de la convivencia matrimonial con el vínculo y no tiene ningún reparo en ignorar la importancia decisiva del consentimiento matrimonial y sus consecuencias entre ellas el bien de la indisolubilidad.

c) Un tercer autor habla de que «El matrimonio nace... el matrimonio muere...» ${ }^{39}$, y trata del problema del fracaso del matrimonio y su posible solución proponiendo la distinción entre matrimonio instaurado y matrimonio consagrado $^{40}$, el primero vendría a ser el que resulta del intercambio del consentimiento y el segundo el grado de perfeccionamiento que los esposos alcanzan en la constitución de la comunidad de vida y amor, esto es en la convivencia matrimonial, si esto segundo no lo conseguirían estamos ante un matrimonio donde no se ha producido la verdadera consumación.

\section{INTERVENCIONES MAGISTERIALES EN RELACIÓN CON LA PASTORAL, EL FRACASO MATRIMONIAL Y LA FINALIDAD DEL PROCESO}

\subsection{Intervenciones magisteriales de San Fuan Pablo II}

En su último discurso a la Rota Romana en el año 2005 San Juan Pablo II ponía en alerta la errónea incidencia en el ámbito del proceso de un supuesto in-

\footnotetext{
37 J. M. Lahidalga AgUiRRe, A propósito de los matrimonios irremediablemente fracasados..., cit., 295-317.

38 IDEM, La declaración de nulidad y el matrimonio cristiano: una solución pastoral, Surge. Revista sacerdotal, espiritualidad y apostolado 543-544 (1993) 48.

39 J. S. Botero GIRALDO, El matrimonio nace... el matrimonio muere... dos posiciones de cara al fracaso conyugal, Theologica xaveriana 173 (2012) 31.

${ }^{40}$ Cfr. ibid., 45.
} 
terés pastoral en atención a los matrimonios fracasados a la hora de emitir el correspondiente juicio: «Con todo, en las circunstancias actuales existe también otro peligro. En nombre de supuestas exigencias pastorales, hay quien ha propuesto que se declaren nulas las uniones que han fracasado completamente. Para lograr ese resultado se sugiere que se recurra al expediente de mantener las apariencias de procedimiento y sustanciales, disimulando la inexistencia de un verdadero juicio procesal. Así se tiene la tentación de proveer a un planteamiento de los motivos de nulidad, y a su prueba, en contraposición con los principios elementales de las normas y del magisterio de la Iglesia. Es evidente la gravedad objetiva jurídica y moral de esos comportamientos, que ciertamente no constituyen la solución pastoralmente válida a los problemas planteados por las crisis matrimoniales [...]. En los discursos anuales a la Rota romana, he recordado muchas veces la relación esencial que el proceso guarda con la búsqueda de la verdad objetiva ${ }^{41}$. Con gran precisión el Papa Juan Pablo II advierte del peligro de interpretar como solución pastoral la declaración de nulidad de los matrimonios fracasados sin atención a la verdad objetiva de la validez o no del vínculo ${ }^{42}$, es más denuncia la tentación de convertir o de reducir el proceso a una simple formalidad que certifique canónicamente el fracaso de la convivencia matrimonial ${ }^{43}$.

${ }^{41}$ JuAn Pablo II, Ad TribunalRotae Romanae iudiciali ineunte anno, Acta Apostolicae Sedis 97 (2005) 164-165: «Tuttavia, nelle attuali circostanze un altro rischio è pure incombente. In nome di pretese esigenze pastorali, qualche voce s'è levata per proporre di dichiarare nulle le unioni totalmente fallite. Per ottenere tale risultato si suggerisce di ricorrere all'espediente di mantenere le apparenze procedurali e sostanziali, dissimulando l'inesistenza di un vero giudizio processuale. Si è così tentati di provvedere ad un'impostazione dei capi di nullità e ad una loro prova in contrasto con i più elementari principi della normativa e del magistero della Chiesa. É evidente l'oggettiva gravità giuridica e morale di tali comportamenti, che non costituiscono sicuramente la soluzione pastoralmente valida ai problemi posti dalle crisi matrimoniali [...]. Nei discorsi annuali alla Rota Romana ho più volte ricordato l'essenziale rapporto che il processo ha con la ricerca della verità oggettiva». Cfr. JUAN PABLO II, Discurso al Tribunal de la Rota Romana con ocasión de la apertura del año judicial, Sábado 29 de enero de 2005, www.vatican.va.

42 Cfr. Coram YaAcoub, sent. diei 18 octobris 2005, n. 6.

43 Coram Cian, sent. diei 16 iulii 2009, sentencia no publicada, n. 13: «In asserendo immaturitate psycho-affectiva relevare malam vitae rationem non sufficit sed demonstratio dependentiae eiusdem a causa naturae psychicae requiritur. Aliter putare est assentiri querelis reiectis a Summo Pontifice: "In nome di pretese esigenze pastorali, qualche voce s'è levata per proporre di dichiarare nulle le unioni totalmente fallite" (IOANNEs PaUlus II, Allocutio ad Rotae Romanae Auditores, diei 29 ianuarii 2005, in O.R. 30-I-2005). Matrimonii nullitas declarari nequit eo quod vita coniugalis in dies difficilior fit, sed eo quod, tempore nuptiarum, coniux onera vitae communis adsumere nequibat, quia obiectum ferebat ad eadem onera adimplenda. Profecto tempore nuptiarum radix et natura mali est inquirenda, de hac re in casu animadvertere possumus deesse testimonia circa veram praenuptialem condicionem anomaliae psychicae viri; immo ex rebus adiunctis ante et postnuptialibus evincitur contrarium, id est eius capacitas. Denique, consortii 
En su discurso a la Rota Romana el año 1987 el Papa Juan Pablo II afirmaba con gran claridad que el fracaso de la unión conyugal «no es nunca en sí mismo jamás una prueba para demostrar la incapacidad de los contrayentes, que pueden haber descuidado, o usado mal, los medios naturales y sobrenaturales a su disposición, o que pueden no haber aceptado las limitaciones inevitables y el peso de la vida conyugal, sea por un bloqueo de naturaleza inconsciente, sea por leves patologías que no afectan a la sustancial libertad humana, sea por fin por deficiencias de orden moral» ${ }^{44}$.

Hay por tanto que distinguir entre el defecto psicológico y el vicio moral; o bien entre la anormalidad psíquica que vicia el consentimiento y la dificultad o divergencia de caracteres entre las partes, de tal manera que la vida común puede resultar costosa: «El matrimonio goza del favor del derecho; por lo que, en la duda, se ha de estar por la validez del matrimonio, mientras no se pruebe lo contrario» ${ }^{45}$, se entiende, efectivamente, de la certeza moral del contrario, que debe constar.

naufragium haud pependit ex aliqua praenuptiali incapacitate viri conventi, sed tantum a causis post matrimonium exortis, inter quas infidelitas eius, discrepantia indolum et ita porro. Deficiente, ergo, probatione cuiuscumque causae quae sufficientem capacitatem assumendi onera iugalia ex viri conventi parte aliquo modo praepedire aut graviter laedere potuerit, concludendum est nullitatem matrimonii, in casu, minime probatam esse».

44 JuAn Pablo II, Ad Rotae romanae auditores coram admissos, Discurso del 5 de febrero 1987 a la Rota romana, Acta Apostolicae Sedis 79 (1987) 1455: «Il fallimento dell'unione coniugale, peraltro, non è mai in sé una prova per dimostrare tale incapacità dei contraenti, i quali possono aver trascurato, o usato male, i mezzi sia naturali che soprannaturali a loro disposizione, oppure non aver accettato i limiti inevitabili ed i pesi della vita coniugale, sia per blocchi di natura inconscia, sia per lievi patologie che non intaccano la sostanziale libertà umana, sia, infine, per deficienze di ordine morale». Coram CABERLETTI, sent. diei 22 ianuarii 2009, sentencia no publicada, n. 6: «Peritia quidem recta anthropolgia niti debet, et proinde omnino reicienda est sententia, etsi nomine scientiae se ornari praesumat, quae determinismo psychico, hominis libertatem negante, fulcitur, vel pro gravitate designanda utitur criteriis quae valde dissimilia sunt ab illis iurisprudentiae canonicae propriis; nam convictus infelix vel coniugii ruina per se nullatenus probare possunt nubentem incapacem fuisse». Coram DE ANGELIS, sent. diei 13 novembris 2008, sentencia no publicada, n. 14: «Dissolutio coniugalis convictus semper causam proximam habet in quibusdam factis determinatis ex parte unius vel utriusque coniugis sed originem remotam quoque habet in animo et conversatione unius vel utriusque partis. Iudicis est non tantum rationes invenire dissolutionis convictus sed praesertim edicere an capacitas consensus in alterutra vel utraque parte defecerit, in casu. Infelix coniugii exitus enim originem quoque habere potest ex multiplici causa etiam extrinseca vel ex non gravi psychica incapacitate contrahentis». Cfr. también coram DE ANGELIS, sent. diei 24 iunii 2009, sentencia no publicada, n. 5.

45 Can. 1060: «Matrimonium gaudet favore iuris; quare in dubio standum est pro valore matrimonii, donec contrarium probetur». Cfr. E. CAPARROS - M. ThÉRIAUlt - J. Thorn, Code of Canon Law Annotated, Wilson \& Lafleur Limitée, Montréal 1993, 661; P. V. PinTo (a cura di), Commentario al Codice di Diritto Canonico, Libreria Editrice Vaticana, Città del Vaticano 2001, 628. 


\subsection{Relación entre preocupación pastoral, fracaso matrimonial y sentido jurídico de la Instrucción «Dignitas Connubii» promulgada el 25 de enero de 2005 con motivo del resultado del Sínodo ordinario sobre la Eucaristía del año 2005}

Es interesante y de gran actualidad para nuestro tema el primer discurso del Papa Benedicto XVI a la Rota Romana del 28 de enero de 2006. En ese discurso afrontó el reto planteado por los Obispos en el Sínodo del año 2005 sobre la Eucaristía y la situación de los divorciados y vueltos a casar, y el hecho de que unos meses antes hubiera sido promulgada la Instrucción Dignitas Connubii ${ }^{46}$. El Papa afirmaba: «A primera vista, podría parecer que la preocupación pastoral que se reflejó en los trabajos del Sínodo y el espíritu de las normas jurídicas recogidas en la Dignitas Connubii son dos cosas profundamente diferentes, incluso casi contrapuestas. Por una parte, parecería que los padres sinodales invitaban a los tribunales eclesiásticos a esforzarse para que los fieles que no están casados canónicamente puedan regularizar cuanto antes su situación matrimonial y volver a participar en el banquete eucarístico. Por otra, en cambio, la legislación canónica y la reciente Instrucción parecerían poner límites a ese impulso pastoral, como si la preocupación principal fuera cumplir las formalidades jurídicas previstas, con el peligro de olvidar la finalidad pastoral del proceso. Detrás de este planteamiento se oculta una supuesta contraposición entre derecho y pastoral en general. No pretendo afrontar ahora a fondo esta cuestión, ya tratada por Juan Pablo II en repetidas ocasiones, sobre todo en el discurso de 1990 a la Rota romana. En este primer encuentro con vosotros prefiero centrarme, más bien, en lo que representa el punto de encuentro fundamental entre derecho y pastoral: el amor a la verdad ${ }^{47}$. Y con gran claridad el Papa Benedicto XVI subraya la ne-

${ }^{46}$ Sobre las novedades introducidas por la Instrucción Dignitas Connubii, cfr. J. GARCÍA FAílde, La instrucción Dignitas Connubii a examen. Texto castellano y comentario de sus artículos, Universidad Pontificia de Salamanca, Salamanca 2006; C. Morán Bustos - C. PeÑa García, Nulidad de matrimonio y proceso canónico. Comentario adaptado a la Instrucción Dignitas Connubii, Dykinson, Madrid 2007; C. PeÑa GarCÍA, La Instrucción Dignitas Connubii y su repercusión en las causas canónicas de nulidad matrimonial, Estudios Eclesiásticos 80 (2005) 645-701; R. RodRíGUEZ CHACóN - L. Ruano Espina (eds.), Los procesos de nulidad de matrimonio canónico boy, Dykinson, Madrid 2006; R. RodrígueZ-OcaÑa - J. SEdano (eds.), Procesos de nulidad matrimonial. La Instrucción Dignitas Connubii, Eunsa, Pamplona 2006; L. SABbarese, Semplicità e celerità nel processo matrimoniale canonico, en Aa.Vv., Il giudizio di nullità matrimoniale dopo l'istruzione «Dignitas Connubii». Parte prima. I principi, Libreria Editrice Vaticana, Città del Vaticano 2007, 261-284.

47 BenEDICTO XVI, Ad Tribunal Rotae Romanae, cit., 136: «Potrebbe sembrare a prima vista che la preoccupazione pastorale riflessa nei lavori del Sinodo e lo spirito delle norme giuridiche raccolte nella Dignitas Connubii divergano profondamente tra di loro, fin quasi a contrapporsi. Da 
cesidad de defender el principio de la indisolubilidad matrimonial y añade: «es engañoso el servicio que se puede prestar a los fieles y a los cónyuges no cristianos en dificultad fortaleciendo en ellos, tal vez sólo implícitamente, la tendencia a olvidar la indisolubilidad de su unión. De ese modo, la posible intervención de la institución eclesiástica en las causas de nulidad corre el peligro de presentarse como mera constatación de un fracaso [...]. Deseo que estas reflexiones ayuden a hacer comprender mejor que el amor a la verdad une la institución del proceso canónico de nulidad matrimonial y el auténtico sentido pastoral que debe animar esos procesos ${ }^{48}$. Estas palabras del Papa Benedicto XVI nos ayudan a comprender mejor las consecuencias negativas que para el reconocimiento del principio de la indisolubilidad tienen cuando se busca convertir el proceso en una especie de trámite que se limite a constatar el fracaso matrimonial que permite a los fieles en situación irregular un nuevo matrimonio canónico. Al contrario, la aplicación justa y equitativa de las normas canónicas, tratando de buscar la verdad jurídica sobre el vínculo contraído expresan la naturaleza pastoral del proceso.

\section{El fracaso matrimonial EN El Mitis IUdEX Dominus IEsus}

En primer lugar, tras un estudio serio del contenido del nuevo Motu Proprio Mitis Iudex Dominus Iesus podemos concluir que éste se encuentra muy lejos de identificar matrimonio fracasado con nulidad. El Papa insiste con gran

una parte, parrebbe che i Padri sinodali abbiano invitato i tribunali ecclesiastici ad adoperarsi affinché i fedeli non canonicamente sposati possano al più presto regolarizzare la loro situazione matrimoniale e riaccostarsi al banchetto eucaristico. Dall'altra parte, invece, la legislazione canonica e la recente Istruzione sembrerebbero, invece, porre dei limiti a tale spinta pastorale, come se la preoccupazione principale fosse quella di espletare le formalità giuridiche previste, con il rischio di dimenticare la finalità pastorale del processo. Dietro a questa impostazione si cela una pretesa contrapposizione tra diritto e pastorale in genere. Non intendo ora riprendere approfonditamente la questione, già trattata da Giovanni Paolo II a più riprese, soprattutto nell'allocuzione alla Rota Romana del 1990. In questo primo incontro con voi preferisco concentrarmi piuttosto su ciò che rappresenta il fondamentale punto di incontro tra diritto e pastorale: l'amore per la verità». Cfr. BEnedicto XVI, Discurso a los Prelados Auditores, Defensores del Vínculo y Abogados de la Rota Romana, Sábado 28 de enero de 2006, www.vatican.va.

48 Benedicto XVI, Ad Tribunal Rotae Romanae, cit., 136: «Proprio per questo motivo è ingannevole il servizio che si può offrire ai fedeli e ai coniugi non cristiani in difficoltà rafforzando in loro, magari solo implicitamente, la tendenza a dimenticare l'indissolubilità della propria unione. In tal modo, l'eventuale intervento dell'istituzione ecclesiastica nelle cause di nullità rischia di apparire quale mera presa d'atto di un fallimento [...]. Mi auguro che queste riflessioni giovino a far comprendere meglio come l'amore alla verità raccordi l'istituzione del processo canonico di nullità matrimoniale con l'autentico senso pastorale che deve animare tali processi». Cfr. Idem, Discurso a los Prelados Auditores, Defensores del Vinculo y Abogados de la Rota Romana, Sábado 28 de enero de 2006, www.vatican.va. 
énfasis en la necesidad de que la Iglesia acoja con caridad y misericordia a aquellos fieles cuyo matrimonio ha fracasado y para alcanzar este objetivo ofrece la nueva reforma en la que hará hincapié en varios principios, el primero de ellos es la defensa de la indisolubilidad, en segundo lugar, reconoce la naturaleza jurídica del proceso de nulidad y también recuerda la necesidad de alcanzar la requerida certeza moral para declarar la nulidad del matrimonio ${ }^{49}$.

El Motu Proprio Mitis Iudex Dominus Iesus recoge la expresión «matrimonio fallido» para referirla a un enorme número de fieles que por encontrarse en esa situación necesitan «un especial cuidado pastoral». En los artículos 1 y 2 de las Reglas de procedimiento se refiere a ellos con las expresiones «cónyuges separados o divorciados» y especifica «que por su condición de vida hayan eventualmente abandonado la práctica religiosa $\gg^{50}$. Denuncia la dificultad de estos fieles para llegar a los tribunales de la Iglesia y para evitarlo señala la necesidad de que sea la Iglesia misma la que tome la iniciativa y se aproxime a ellos con caridad y misericordia intentado superar aquellas barreras físicas o morales que les impiden acercarse a la justicia eclesiástica ${ }^{51}$. Es muy importante destacar las

49 Cfr. C. PeÑa GarCía, La reforma de los procesos canónicos de nulidad matrimonial: el M. P. «Mitis Iudex Dominus Iesus», Estudios Eclesiásticos 90 (2015) 621-682.

${ }^{50}$ Francisco, Mitis Iudex Dominus Iesus, Reglas de procedimiento para tratar las causas de nulidad de matrimonio, art. 1: «El Obispo en virtud del can. $383 \$ 1$ está obligado a acompañar con ánimo apostólico a los cónyuges separados o divorciados, que por su condición de vida hayan eventualmente abandonado la práctica religiosa. Por lo tanto, comparte con los párrocos (cfr. can. $529 \$ 1$ ) la solicitud pastoral hacia estos fieles en dificultad». Cfr. P. A. MorENO GarCía, El servicio de indagación prejudicial: aspectos jurídico-pastorales, Ius Canonicum 56 (2016) 65-85.

51 La situación de colapso de algunos tribunales constituía una situación ciertamente grave para los derechos de los fieles, puesta de manifiesto por la doctrina procesalista, que lleva varios años sugiriendo cauces de mejora y agilización de los procesos. Cfr. A. DE ANGELIS, Propuestas para una más rápida resolución de las causas matrimoniales (con particular referencia a las cuestiones incidentales, al proceso breve y a la ausencia de parte), en Asociación EsPañola DE CANONISTAS, Procesos matrimoniales canónicos, Dykinson, Madrid 2014, 115-140; M. Calvo Tojo, Reforma del proceso matrimonial anunciada por el Papa, Universidad Pontificia de Salamanca, Salamanca 1999; C. GULLO, Celerità e gratuità dei processi matrimoniali canonici, en AA.Vv., La giustizia nella Chiesa: fondamento divino e cultura processualistica moderna, Libreria Editrice Vaticana, Città del Vaticano 1997, 229-244; J. LlOBELL, Suggerimente per attuare le possibilità offerte dalla vigente normativa per rendere più celeri le cause di nullità matrimoniale, en H. FRANCESCHI - M. Á. ORTIZ (eds.), La ricerca della verità sul matrimonio e il diritto a un processo giusto e celere, EDUSC, Roma 2012, 387402; G. P. MonTinI, Devono durare anni le cause di nullità matrimoniale? Suggerimenti e proposte per un processo più celere. La formulazione del dubbio, Quaderni di diritto ecclesiale 20 (2007) 436442; C. PeÑa GaRCÍA, Derecho a una justicia eclesial rápida: sugerencias de iure condendo para agilizar los procesos canónicos de nulidad matrimonial, Revista Española de Derecho Canónico 67 (2010) 739-767; A. STANKIEWICZ, La celerità nelle cause di nullità matrimoniale: aspetti operativi, en H. FRANCESCHI - M. Á. ORTIZ (eds.), Ius et matrimonium. Temi di diritto matrimoniale e processuale canonico, EDUSC, Roma 2015, 217-236; L. G. WRENn, A New Procedural Law for Marriage 
palabras del Papa en la introducción a las Reglas de procedimiento cuando reconoce que el punto de encuentro entre la preocupación por los fieles que han sufrido la ruptura de su matrimonio y el proceso de nulidad es el amor a la verdad, cuando concluye que el fin del proceso es: «la verificación de la verdad sobre la existencia o no del vínculo de su matrimonio fallido» ${ }^{52}$.

Es sabido que el Mitis Iudex Dominus Iesus recoge en gran medida las peticiones de las Conferencias episcopales y de los Padres sinodales expuestas en la Relatio synodi del año $2014^{53}$; en ellas se invitaba a los tribunales eclesiásticos a esforzarse por atender judicialmente a tantos fieles en situación irregular. Pues bien la reforma introducida por el Papa Francisco viene estimulada por el enorme número de fieles que habiendo visto fracasar su matrimonio esperan una solución que tranquilice sus conciencias ${ }^{54}$. La nueva regulación introducida por el Motu proprio surge como un intento de respuesta de mayor efi-

Cases?, The Jurist 62 (2002) 195-210; A. ZAMBON, Devono durare anni le case di nullità matrimoniale? Suggerimenti e proposte per un processo célere. L'uso del computer durante l'istruttoria, Quaderni di diritto ecclesiale 25 (2012) 369-379.

52 Tienen especial importancia para la correcta comprensión de la reforma estas palabras del Papa Francisco: «La III Asamblea General Extraordinaria del Sínodo de los Obispos, celebrada en el mes de octubre de 2014, constató la dificultad de los fieles para llegar a los tribunales de la Iglesia. Puesto que el Obispo, como el buen Pastor, está obligado a ir al encuentro de sus fieles que tienen necesidad de un especial cuidado pastoral, junto con las normas detalladas para la aplicación del proceso matrimonial, ha parecido oportuno, dando por cierta la colaboración del Sucesor de Pedro y de los Obispos en la difusión del conocimiento de la ley, ofrecer algunos instrumentos a fin de que la tarea de los tribunales pueda responder a la exigencia de los fieles, que piden la verificación de la verdad sobre la existencia o no del vínculo de su matrimonio fallido» (FrancIsco, Mitis Iudex Dominus Iesus, Reglas de procedimiento para tratar las causas de nulidad de matrimonio). Sobre el contenido y desarrollo de la Asamblea extraordinaria, cfr. C. PEÑA GARCía, El Sínodo de la Familia: memoria, análisis y expectativas, Misión Joven 462-463 (2015) 2732 y 49-54; IDEM, El Sínodo extraordinario de la familia: impresiones y retos, Razón y fe 270 (2014) 569-582.

53 P. V. PINTo, Nota editoriale, Quaderni dello Studio Rotale 23 (2016) 5: «La legge ordinata nei M. P. Mitis et misericors Fesus e Mitis Iudex Dominus Fesus insieme ai due Rescritti successivi succitati, fu preannunzio dell'Esortazione post-sinodale Amoris Laetitia, ambedue frutto del doppio cammino sinodale». Cfr. también P. V. PINTO, Speranze non paure, Quaderni dello Studio Rotale 23 (2016) 65-67; C. PeÑa GaRCía, Agilización de los procesos canónicos de nulidad matrimonial: de las propuestas presinodales al motu proprio Mitis Iudex Dominus Iesus y retos pendientes tras la reforma, Ius Canonicum 56 (2016) 41-64.

54 Francisco, Mitis Iudex Dominus Iesus, Proemio: «Alimenta el estímulo reformador el enorme número de fieles que, aunque deseando proveer a la propia conciencia, con mucha frecuencia se desaniman ante las estructuras jurídicas de la Iglesia, a causa de la distancia física o moral; por tanto, la caridad y la misericordia exigen que la misma Iglesia como madre se haga accesible a los hijos que se consideran separados». Cfr. P. V. PINTO, La riforma del processo matrimoniale per la dichiarazione di nullità voluta e decisa da Papa Francesco, Quaderni dello Studio Rotale 23 (2016) 57-62. 
cacia ante la realidad del fracaso matrimonial entre los católicos, podemos decir que uno de los principios en los que se inspira es el impulso pastoral que busca salir en ayuda de aquellos fieles que habiéndose roto su unión matrimonial sufren las consecuencias de la ruptura familiar.

$Y$ en estrecha conexión con lo anterior el Papa advierte del posible desaliento de muchos fieles en situación irregular ante las estructuras jurídicas de la Iglesia, a causa de la distancia física o moral, esto exige que sea la misma Iglesia, que, como madre, en atención a la misericordia y a la caridad se haga presente. Todo ello exige un cambio en el modo en el que los tribunales deben hacerse más accesibles en el marco general de la pastoral familiar y en el funcionamiento de los organismos diocesanos, con frecuencia el tribunal y su actividad aparecen relegados como una especie de servicio técnico de segundo orden, lo cual en cierto modo va en perjuicio de los fieles necesitados de la asistencia judicial y que ven el ejercicio de la justicia eclesiástica como una barrera infranqueable. En todo caso el Papa Francisco manifiesta su preocupación por aquellos fieles necesitados de una justicia cercana y accesible.

Como ya hemos señalado, el Motu Proprio Mitis Iudex Dominus Iesus, refleja las aportaciones que las Conferencias episcopales y las que posteriormente los Padres sinodales fueron presentando en el Sínodo extraordinario sobre la familia celebrado el año 2014. El mismo Papa Francisco recuerda en el proemio del Motu proprio como «se dirigieron también los votos de la mayoría de mis Hermanos en el Episcopado reunidos en la reciente asamblea extraordinaria del Sínodo, que solicitaron procesos más rápidos y accesibles» ${ }^{55}$. Y añade recalcando la importancia de la contribución de los trabajos del Sínodo: «En total sintonía con esos deseos, he decidido establecer con este Motu proprio disposiciones con las cuales se favorezca no la nulidad de los matrimonios, sino la celeridad de los procesos y, no en menor medida, una adecuada simplificación ${ }^{56}$. El Papa en sintonía con lo pedido por los Obispos ofrece por medio de la reforma nuevos mecanismos procesales que eviten una duración injustificada de los procesos prolongándolos innecesariamente, de este modo introduce una mayor simplificación con la abolición de la doble conforme y una mayor celeridad en general y en concreto con la creación del proceso más breve pero al mismo tiempo reafirma con claridad que esta simplificación y celeridad no van dirigidos a favorecer la nulidad de los matrimonios, sino su juicio con plena adecuación a la verdad.

${ }^{55}$ Francisco, Mitis Iudex Dominus Iesus, Proemio.
${ }^{56}$ Francisco, Mitis Iudex Dominus Iesus, Proemio. 
El Papa reafirma el principio de la indisolubilidad del vínculo matrimonial especificando con claridad que este principio inspira el espíritu de la reforma y como las causas de nulidad y la evolución del proceso responden a la defensa de la indisolubilidad como servicio al bien de las almas que es la suprema ley del derecho. Al mismo tiempo que destaca la importancia de la indisolubilidad del vínculo matrimonial afirma que el matrimonio es el eje y origen de la familia cristiana: «Con el correr de los siglos, la Iglesia, adquiriendo una conciencia más clara en materia matrimonial de las palabras de Cristo, ha entendido y expuesto con mayor profundidad la doctrina de la indisolubilidad del sagrado vínculo conyugal, ha sistematizado las causas de nulidad del consentimiento matrimonial y ha reglamentado más adecuadamente el proceso judicial correspondiente, de modo que la disciplina eclesiástica fuera siempre más coherente con la verdad de fe profesada. Todo esto se ha hecho siempre teniendo como guía la ley suprema de la salvación de las almas» ${ }^{57}$.

El Papa hace constar su voluntad de que las causas de nulidad matrimonial sigan el proceso judicial declarativo no porque lo exija la naturaleza del asunto sin por proteger con mayor eficacia el vínculo sacramental: «que las causas de nulidad sean tratadas por vía judicial, y no administrativa, no porque lo imponga la naturaleza de la cosa, sino más bien porque lo exige la necesidad de tutelar en el máximo grado la verdad del vínculo sagrado: y eso se asegura precisamente con las garantías del orden judicial» ${ }^{58}$. El mismo Papa Francisco el 12 de marzo de 2016 dirigiéndose a los participantes de un curso organizado por la Rota Romana decía: «con la reforma del proceso matrimonial por mi promulgada, he querido cerrarla para siempre al proceso administrativo, porque sería la puerta que se abre al así llamado "divorcio eclesiástico". No, nunca el proceso administrativo en materia matrimonial; siempre el procedimiento judicial. Es un punto importante; los casos de nulidad se tratan judicialmente, sea por el proceso más breve sea por el proceso ordinario [...]; porque el matrimonio es indisoluble e intocable y esto debe quedar claro para todos» ${ }^{59}$.

El Papa Francisco siguiendo la línea de sus predecesores insiste en la necesidad de la certeza moral que debe alcanzarse tanto sobre el derecho aplicable como sobre los hechos, hechos que deben encontrar su apoyo en el derecho para que la certeza moral sea correctamente recibida. Así lo recoge en el

\footnotetext{
57 Ibid.

58 Francisco, Mitis Iudex Dominus Iesus, Proemio.

59 IDEM, Mens legislatoris del 12 marzo 2016, Quaderni dello Studio Rotale 23 (2016) 51-52.
} 
artículo 12 de las reglas de procedimiento: «Para la certeza moral necesaria conforme a derecho no basta el peso prevalente de las pruebas y de los indicios, sino que se requiere también que se excluya cualquier prudente duda positiva de error, tanto en cuanto al derecho como en cuanto a los hechos, aunque no quede eliminada la mera posibilidad de lo contrario» ${ }^{60}$. El mismo Papa Francisco en un discurso dirigido a los participantes en un curso organizado por la Universidad Gregoriana afirmaba que la meta del proceso es la certeza moral: ésta requiere que quede del todo excluido cualquier duda prudente positiva de error, aunque no quede excluida la mera posibilidad de lo contrario ${ }^{61}$. Tanto esta afirmación del Papa como lo regulado en el citado art. 12 es muy relevante porque confirma normativamente los dos aspectos que deben componer la certeza moral. La meta del proceso es que el juez alcance la certeza moral que dice relación a los hechos que provocan la nulidad del matrimonio, esto es la quaestio facti y además a la norma que establece la naturaleza invalidante de los hechos probados, esto es a la quaestio iuris en cuanto necesaria manifestación de la naturaleza objetiva y en consecuencia declarativa de la decisión sobre la nulidad del matrimonio.

\section{El FRACASo Matrimontal EN La EXHORTACión ApOstólica AMORIS LAETITIA}

Es necesario poner de manifiesto que la Exhortación en ningún apartado identifica «fracaso» conyugal con nulidad matrimonial. La Exhortación apostólica impresiona por su amplitud y articulación. El capítulo octavo constituye una invitación a la misericordia y al discernimiento pastoral frente a situaciones que no responden plenamente a aquello que el Señor propone. El Papa que escribe usa tres verbos muy importantes: «acompañar, discernir e integrar» que son fundamentales para afrontar situaciones de fragilidad, complejas o irregulares. Entonces el Papa presenta la necesaria gradualidad en la pastoral, la importancia del discernimiento, las normas y circunstancias atenuantes en el discernimiento pastoral y, en fin, aquella que él define la «ló-

${ }^{60}$ IDEM, Mitis Iudex Dominus Iesus, Reglas de procedimiento para tratar las causas de nulidad de matrimonio, art. 12.

${ }^{61}$ Cfr. IDEM, Ad Facultatem Iuris Canonici Pontificiae Universitatis Gregorianae, Acta Apostolicae Sedis 107 (2015) 192: «Uno svolgimento sicuro perché indica e spiega con chiarezza la meta del processo stesso, ossia la certezza morale: essa richiede che resti del tutto escluso qualsiasi dubbio prudente positivo di errore, anche se non è esclusa la mera possibilità del contrario». 
gica de la misericordia pastoral». El capítulo octavo es muy delicado. Para leerlo se debe recordar que «a menudo, la tarea de la Iglesia asemeja a la de un hospital de campaña» ${ }^{62}$. En la última sección del capítulo: La lógica de la misericordia pastoral, Papa Francisco, para evitar equívocos, reafirma con fuerza: «Comprender las situaciones excepcionales nunca implica ocultar la luz del ideal más pleno ni proponer menos que lo que Jesús ofrece al ser humano. Hoy, más importante que una pastoral de los fracasos es el esfuerzo pastoral para consolidar los matrimonios y así prevenir las rupturas» ${ }^{63}$. Pero el sentido general del capítulo y del espíritu que el Papa quiere imprimir a la pastoral de la Iglesia está bien resumido en las palabras finales: «Invito a los fieles que están viviendo situaciones complejas, a que se acerquen con confianza a conversar con sus pastores o con laicos que viven entregados al Señor. No siempre encontrarán en ellos una confirmación de sus propias ideas o deseos, pero seguramente recibirán una luz que les permita comprender mejor lo que les sucede y podrán descubrir un camino de maduración personal. E invito a los pastores a escuchar con afecto y serenidad, con el deseo sincero de entrar en el corazón del drama de las personas y de comprender su punto de vista, para ayudarles a vivir mejor y a reconocer su propio lugar en la Iglesia» ${ }^{64}$.

\section{CONCLUSIÓN}

Como consecuencia de este trabajo y a la luz de todo lo expuesto consideramos que la relación entre fracaso matrimonial y proceso sigue siendo la misma: el amor a la verdad, esto es la búsqueda por medio del proceso judicial de nulidad la verdad sobre la validez o no del consentimiento conyugal emiti$\mathrm{do}^{65}$. El punto real de encuentro entre la naturaleza declarativa del proceso de nulidad y la pastoral viene constituido igualmente por el amor a la verdad sobre la nulidad o no del vínculo sagrado. Como ya hemos recordado en los apartados anteriores el Magisterio Pontificio pone en guardia frente a errados conceptos de aplicación pastoral al matrimonio fracasado. Este estudio puede conducirnos a concluir que la verdadera relevancia del fracaso matrimonial no está en el ámbito del proceso sino en el ámbito de la pastoral familiar, de ahí que el título más acertado de esta ponencia hubiera sido la relevancia pastoral

\footnotetext{
62 IDEM, Exort. Apost. Postsinodal Amoris Laetitia, n. 291.

63 IDEM, Exort. Apost. Postsinodal Amoris Laetitia, n. 307.

64 Ibid., n. 312.

65 Cfr. P. Moneta, La giustizia nella Chiesa, Il Mulino, Bologna 2002, 71-75.
} 
del fracaso de las relaciones interpersonales, pues es en este ámbito donde deben tratar de ser combatidos tales fracasos y buscar la solución más correcta.

Los fieles cuyo enlace ha fracasado y someten la validez de su matrimonio al tribunal de la Iglesia tiene el derecho a ser juzgados servatis iuris praescriptis, pero conforme al parágrafo segundo del can. 221, también, cum aequitate servandis ${ }^{66}$. Ahora bien, la aplicación de las normas con equidad no significa una aplicación edulcorada o superficialmente benévola de la ley o con una falsa atenuación pastoral que llevaría a un malentendido sentimentalismo o compasión con una visión pietista de la caridad evangélica ${ }^{67}$. No se trata de pasar de un plano jurídico a un plano meramente pastoral. Juzgar con equidad significa tomar plena conciencia que la justicia y el mismo derecho, como señaló Juan Pablo II, son realidades intrínsecamente pastorales y que la actividad jurídico-canónica es por su propia naturaleza pastoral ${ }^{68}$. Así entendida, la naturaleza pastoral y equitativa de la justicia eclesiástica nos conduce a comprender las palabras del Papa Francisco, cuando el día 12 de marzo de 2016 afirmaba que «los documentos Mitis Iudex Dominus Iesus y Mitis et Misericors Iesus, que han recogido los frutos del trabajo de la comisión especial instituida el 27 de agosto de 2014: casi un año de trabajo. Tales disposiciones tienen un objetivo eminentemente pastoral: mostrar la solicitud de la Iglesia hacia los fieles que esperan una rápida verificación de su situación matrimonial [...]. Es importante que la nueva normativa sea acogida y profundizada, en el contenido y en el espíritu, especialmente por los agentes de los Tribunales eclesiásticos, para ofrecer un servicio de justicia y de caridad a las familias. Para mucha gente, que ha vivido una experiencia matrimonial no feliz, la verificación de la validez o no del matrimonio representa una posibilidad importante; y estas personas deben ser ayudadas a recorrer el camino de la forma más ágil posible» ${ }^{69}$.

${ }^{66}$ Can. 221: «Christifidelibus ius quoque est ut, si ad iudicium ab auctoritate competenti vocentur, iudicentur servatis iuris praescriptis, cum aequitate applicandis». Cfr. E. CAPARROS - M. THÉRiault - J. Thorn, Code of Canon Law Annotated, cit., 195-196; P. V. Pinto (a cura di), Commentario al Codice di Diritto Canonico, cit., 128-129; C. VAQUero, Derecho a la tutela judicial efectiva en las causas canónicas de nulidad matrimonial, en C. PEÑa GARCía (ed.), Retos del Derecho Canónico en la sociedad actual, Dykinson, Madrid 2012, 189-208.

${ }^{67}$ Cfr. P. MoneTA, Giudizio di nullità di matrimonio e vita coniugale, en IDEM, Communitas vitae et amoris. Scritti di diritto matrimoniale canonico, cit., 146-147.

${ }^{68}$ Cfr. Juan Pablo II, Ad Romanae Rotae Praelatos, auditores, officiales et advocatos anno iudiciali ineunte, cit., 874: «La dimensione giuridica e quella pastorale sono inseparabilmente unite nella Chiesa pellegrina su questa terra. Anzitutto, vi è una loro armonia derivante dalla comune finalità: la salvezza delle anime. Ma vi è di più. In effetti, l'attività giuridico-canonica è per sua natura pastorale».

${ }^{69}$ FranCISCO, Mens legislatoris del 12 marzo 2016, cit., 49-50. 


\section{Bibliografía}

Benedicto XVI, Ad sodales Tribunalis Romanae Rotae, Acta Apostolicae Sedis 101 (2009).

—, Ad Tribunal Rotae Romanae, Acta Apostolicae Sedis 98 (2006).

—, Discurso a los Prelados Auditores, Defensores del Vínculo y Abogados de la Rota Romana, Sábado 28 de enero de 2006, www.vatican.va.

—, Discurso al Tribunal de la Rota Romana con motivo de la inauguración del año judicial, Sala Clementina, Jueves 29 de enero de 2009, www.vatican.va.

Botero GIRALDO, J. S., El matrimonio nace... el matrimonio muere... dos posiciones de cara al fracaso conyugal, Theologica xaveriana 173 (2012).

CABERLETTI, sent. diei 22 ianuarii 2009, sentencia no publicada.

Calvo Tojo, M., Reforma del proceso matrimonial anunciada por el Papa, Universidad Pontificia de Salamanca, Salamanca 1999.

Caparros, E. - Thériault, M. - Thorn, J., Code of Canon Law Annotated, Wilson \& Lafleur Limitée, Montréal 1993.

CIANI, sent. diei 16 iulii 2009, sentencia no publicada.

Concilium Oecumenicum Vaticanum II, Const. dogm. de Ecclesia Lumen Gentium, Acta Apostolicae Sedis 57 (1966) 16.

-, Const. past. de Ecclesia in mundo buius temporis Gaudium et spes, Acta Apostolicae Sedis 58 (1966) 1067.

Codex Iuris Canonici, Constitutio Apostolica Ioannis Pauli PP. II «Sacrae disciplinae leges», 25 Ianuarii 1983.

De ANGELIS, A., Propuestas para una más rápida resolución de las causas matrimoniales (con particular referencia a las cuestiones incidentales, al proceso breve y a la ausencia de parte), en AsOCIACIÓN ESPAÑOLA DE CANONISTAS, Procesos matrimoniales canónicos, Dykinson, Madrid 2014.

—, sent. diei 12 novembris 2008, RRDec., vol. C.

—, sent. diei 13 novembris 2008, sentencia no publicada.

—, sent. diei 24 iunii 2009, sentencia no publicada.

—, sent. diei 25 iunii 2009, RRDec., vol. CI.

ERrÁZURIZ M., C. J., Matrimonio y justicia objetiva en la comunión eclesial: un aspecto del discernimiento pastoral propiciado por «Amoris Laetitia», Ius Canonicum 56 (2016).

Francisco, Ad Facultatem Iuris Canonici Pontificiae Universitatis Gregorianae, Acta Apostolicae Sedis 107 (2015) 192. 
—, Carta Apostólica en forma de «Motu Proprio» Mitis Iudex Dominus Iesus, sobre la reforma del proceso canónico para las causas de declaración de nulidad del matrimonio en el Código del Derecho Cánonico.

-, Discurso a los participantes en un curso organizado por el Tribunal del la Rota Romana, Sábado 12 de marzo de 2016, www.vatican.va.

—, Exhortación apostólica Postsinodal Amoris Laetitia.

—, Mens legislatoris del 12 marzo 2016, Quaderni dello Studio Rotale 23 (2016).

García FAílDE, J., La instrucción Dignitas Connubii a examen. Texto castellano y comentario de sus artículos, Universidad Pontificia de Salamanca, Salamanca 2006.

GIL Hellín, F., Il matrimonio e la vita coniugale, Libreria Editrice Vaticana, Città del Vaticano 1996.

GRILlO, A., Matrimonios indisolubles y matrimonios fracasados, un reto para la pastoral: teología con visión de futuro y teología corta de vista, Phase. Revista de pastoral litúrgica 324 (2014).

Gullo, C., Celerità e gratuità dei processi matrimoniali canonici, en AA.Vv., La giustizia nella Chiesa: fondamento divino e cultura processualistica moderna, Libreria Editrice Vaticana, Città del Vaticano 1997.

Heredia Esteban, sent. diei 16 iulii 2015, sentencia no publicada.

—, sent. diei 29 octobris 2012, sentencia no publicada.

Hervada, J. - Lombardía, P., El Derecho del Pueblo de Dios. Derecho matrimonial, Eunsa, Pamplona 1973.

Hervada, J., Esencia del matrimonio y consentimiento matrimonial, Persona y Derecho 9 (1982).

—, Una caro. Escritos sobre el matrimonio, Eunsa, «Instituto de Ciencias para la Familia», Pamplona 2000.

JuAn Pablo II, Ad Romanae Rotae Praelatos, auditores, officiales et advocatos anno iudiciali ineunte, Discurso del 18 de enero 1990 a la Rota romana, Acta Apostolicae Sedis 82 (1990).

—, Ad Rotae romanae auditores coram admissos, Discurso del 5 de febrero 1987 a la Rota romana, Acta Apostolicae Sedis 79 (1987).

—, Ad Tribunal Rotae Romanae iudiciali ineunte anno, Acta Apostolicae Sedis 97 (2005).

—, Discurso al Tribunal de la Rota Romana con ocasión de la apertura del año judicial, Sábado 29 de enero de 2005, www.vatican.va.

Lahidalga Aguirre, J. M., A propósito de los matrimonios irremediablemente fracasados: una bipótesis de trabajo, Scriptorium victoriense 40 (1993). 
—, La declaración de nulidad y el matrimonio cristiano: una solución pastoral, Surge. Revista sacerdotal, espiritualidad y apostolado 543-544 (1993).

LLOBELL, J., Suggerimente per attuare le possibilità offerte dalla vigente normativa per rendere più celeri le cause di nullità matrimoniale, en H. FRANCESCHI M. Á. ORTIZ (eds.), La ricerca della verità sul matrimonio e il diritto a un processo giusto e celere, EDUSC, Roma 2012.

Moneta, P., Giudizio di nullità di matrimonio e vita coniugale, en IDEM, Communitas vitae et amoris. Scritti di diritto matrimoniale canonico, Pisa University Press, Pisa 2013.

—, La giustizia nella Chiesa, Il Mulino, Bologna 2002.

-, Nullità e fallimento del matrimonio, en IDEM, Communitas vitae et amoris. Scritti di diritto matrimoniale canonico, Pisa University Press, Pisa 2013.

Montini, G. P., Devono durare anni le cause di nullità matrimoniale? Suggerimenti e proposte per un processo più celere. La formulazione del dubbio, Quaderni di diritto ecclesiale 20 (2007).

Morán Bustos, C. M., Retos de la reforma procesal de la nulidad del matrimonio, Ius Canonicum 56 (2016).

Morán Bustos, C. M. - PeÑa García, C., Nulidad de matrimonio y proceso canónico. Comentario adaptado a la Instrucción Dignitas Connubii, Dykinson, Madrid 2007.

Moreno García, P. A., El servicio de indagación prejudicial: aspectos jurídicopastorales, Ius Canonicum 56 (2016).

OrTiZ, M. Á., Capacità consensuale ed essenza del matrimonio, Ius Ecclesiae 21 (2009).

—, La capacità consensuale nel recente Magistero pontificio. Introduzione ai lavori, en H. Franceschi - M. Á. OrTIZ, Discrezione di giudizio e capacità di assumere: la formulazione del canone 1095, Giuffrè Editore, Milano 2013.

Peña García, C., Agilización de los procesos canónicos de nulidad matrimonial: de las propuestas presinodales al motu proprio Mitis Iudex Dominus Iesus y retos pendientes tras la reforma, Ius Canonicum 56 (2016).

-, Derecho a una justicia eclesial rápida: sugerencias de iure condendo para agilizar los procesos canónicos de nulidad matrimonial, Revista Española de Derecho Canónico 67 (2010).

-, El fracaso del matrimonio. Respuestas jurídicas civiles y canónicas y consideraciones pastorales, en A. Berástegut Pedro-Viejo - B. Gómez Bengoechea (coords.), Horizontes de la familia ante el S. XXI. Reflexiones con motivo del XXV aniversario del Instituto Universitario de la Familia, Universidad Pontificia Comillas, Madrid 2011. 
—, El Sínodo de la Familia: memoria, análisis y expectativas, Misión Joven 462463 (2015).

—, El Sínodo extraordinario de la familia: impresiones y retos, Razón y fe 270 (2014).

-, La Instrucción Dignitas Connubii y su repercusión en las causas canónicas de nulidad matrimonial, Estudios Eclesiásticos 80 (2005).

—, La reforma de los procesos canónicos de nulidad matrimonial: el M. P. «Mitis Iudex Dominus Iesus», Estudios Eclesiásticos 90 (2015).

PINTo, P. V. (a cura di), Commentario al Codice di Diritto Canonico, Libreria Editrice Vaticana, Città del Vaticano 2001.

—, La riforma del processo matrimoniale per la dichiarazione di nullità voluta e decisa da Papa Francesco, Quaderni dello Studio Rotale 23 (2016).

—, Nota editoriale, Quaderni dello Studio Rotale 23 (2016).

—, Speranze non paure, Quaderni dello Studio Rotale 23 (2016).

Rodríguez Chacón, R. - RuANo Espina, L. (eds.), Los procesos de nulidad de matrimonio canónico boy, Dykinson, Madrid 2006.

Rodríguez-Ocaña, R. - Sedano, J. (eds.), Procesos de nulidad matrimonial. La Instrucción Dignitas Connubii, Eunsa, Pamplona 2006.

SABBARESE, L., Semplicità e celerità nel processo matrimoniale canonico, en AA.Vv., Il giudizio di nullità matrimoniale dopo l'istruzione «Dignitas Connubii». Parte prima. I principi, Libreria Editrice Vaticana, Città del Vaticano 2007.

STAFFa, D., Iurisprudentia Supr. Tribunalis Signaturae Apost. Dioecesis Ultraiecten. Nullitatis matrimonii (29 nov. 1975), Periodica de re morali canonica liturgica 65 (1977).

STANKIEWICZ, A., La celerità nelle cause di nullità matrimoniale: aspetti operativi, en H. FranCESCHI - M. Á. OrTIZ (eds.), Ius et matrimonium. Temi di diritto matrimoniale e processuale canonico, EDUSC, Roma 2015.

Vaquero, C., Derecho a la tutela judicial efectiva en las causas canónicas de nulidad matrimonial, en C. PeÑa GaRCÍA (ed.), Retos del Derecho Canónico en la sociedad actual, Dykinson, Madrid 2012.

VIANA, A., ¿Son idóneos para el oficio eclesiástico los divorciados que contraen nuevo matrimonio civil?, Ius Canonicum 56 (2016).

Wrenn, L. G., A New Procedural Law for Marriage Cases?, The Jurist 62 (2002).

YAACOUB, sent. diei 18 octobris 2005.

ZAmbOn, A., Devono durare anni le case di nullità matrimoniale? Suggerimenti e proposte per un processo célere. L'uso del computer durante l'istruttoria, Quaderni di diritto ecclesiale 25 (2012). 
OTROS ESTUDIOS 
